\title{
Examining the effect of speed, roadside features, and roadway geometry on crash experience along a rural corridor
}

\author{
Donald C. Watson Jr. • Ahmed Al-Kaisy • \\ Nathan D. Anderson
}

Received: 28 November 2013/Revised: 2 March 2014/Accepted: 7 March 2014/Published online: 28 March 2014

(C) The Author(s) 2014. This article is published with open access at Springerlink.com

\begin{abstract}
This paper presents a current investigation into crash experience along a 15.7-mile rural corridor in southwest Montana with the aim of better understanding crash causal factors along the corridor. The study utilized ten years of crash data, geometric data, and observed freeflow speed data along the corridor. A systematic approach was used where every tenth of a mile was described in term of the crash experience, speed, alignment, and roadside features. Using bivariate and multivariate statistical analyses, the study investigated the crash experience along the corridor as well as some of the underlying relationships which could explain some of the crash causal factors. Results show a strong association between crash rates and horizontal curvatures even for flat curves that can be negotiated at speeds above the posted speed limit, per the highway design equations. Higher crash rates were also found to be associated with the difference between the observed free-flow speeds and the speed dictated by the curve radius or sight distance as per the design equations. Further, results strongly support the safety benefits of guardrails as evidenced by the lower crash rates and severities. The presence of fixed objects and the steepness of side slopes were also found to have an effect on crash rates and severities.
\end{abstract}

D. C. Watson Jr.

289 North Lake Lulu Drive, Winter Haven, FL 33880, USA

A. Al-Kaisy ( $₫)$

Western Transportation Institute, Montana State University, 213

Cobleigh Hall, Bozeman, MT 59717, USA

e-mail: aalkaisy@ce.montana.edu

N. D. Anderson

16304 South Yancey Lane, Spangle, WA 99031, USA
Keywords Crashes - Rural - Analysis - Alignment . Speed $\cdot$ Roadside

\section{Introduction}

The highway system in the U.S. is critical for the economic and social development in this country as it allows for people and goods to travel efficiently in rural and urban areas as well as between towns and cities. However, this high level of mobility for people and goods comes at a remarkable price as suggested by the recent crash statistics. Vehicle collisions cost the U.S. billions of dollars each year, and resulted in an estimated 34,080 fatalities in 2012 [1]. Therefore, improving safety on the highway system has been one of the priorities at the national level. For the traffic safety professional community, it is of critical value to understand the association between crash occurrence and other related variables such as highway geometry, roadside features, driver characteristics, and environmental factors. To this end, two different approaches are typically employed. Site-specific crash analyses at high-crash locations are used with the objective of identifying the underlying crash contributory factors at those locations. The second type of analysis is more aggregate in nature, and crashes are characterized on a highway network with the objective of discerning trends and patterns between crash occurrence and any of the variables mentioned earlier. While the first type of analysis is more microscopic in that the analysis focuses on a single site, the latter is more macroscopic as the analysis addresses the whole network of the highway system at the city, state, or national level. The data required for each analysis type are different in terms of the level of detail and the availability of accurate location information. 
The research presented in this paper is concerned with a new approach in analyzing crash data along an extended stretch of a rural corridor that is known to have higherthan-average crash experience. The approach used in this study is macroscopic in that it examined the whole corridor systematically without focusing on any specific crash or any particular site. However, the approach can also be viewed as microscopic in that detailed crash-related information at a relatively high resolution was used where every tenth of a mile was characterized as an individual segment within the corridor.

\section{Background}

In this section, the most important studies that attempted to establish the relationship between crash experience and any of the underlying variables as related to roadway and traffic attributes are presented. Further, the analysis of non-intersection highway segments in regards to segment length is also presented. Anderson and Krammes [2] discovered that curves with a degree of curvature greater than 4 had higher accident rates. These curves required speed reductions, while curves with lower values did not. Similar results were found by Lamm et al [3]. Conversely, a study on roads in Virginia observed a decrease in sideswipe and run-off-theroad crashes (ROR) with an increase in curvature [4]. Radius was also shown to affect accident rates as Caliendo and Lamberti [5] noticed a decrease in accident rates with the increase in radius for radii between 200 and $500 \mathrm{~m}$. Cenek et al. [6] observed this relationship for a wider range of radii, while Hauer [7] observed this relationship for all radii. Hauer also found that curves with large deflection angles are more hazardous than those with smaller values. A few other studies evaluated other geometric variables such as lane width, shoulder width, pavement type, skid resistance, annual average daily traffic (AADT), spiral transitions, and passing behavior [6, 8-14]. Another two articles described the relationship between speed and curvature [15, 16]. Another study by Tate and Turner found that the difference between the negotiation speed and design speed on curves was strongly related to the injury crash rate [17]. Negotiation speed was defined as the 85th percentile speed of free-flow vehicles (those with headways greater than 6 seconds). Results showed that as the difference in speed exceeded $15-20 \mathrm{~km} / \mathrm{h}$, crash rates increased significantly and that this relationship deteriorated when non-injury crashes were included. Other studies compared accident rates to standard deviation of speed, mean speed reduction, and difference between operating speed and speed limit $[2,4,18,19]$. These studies derived similar conclusions.

The relationship between operating speed and accident frequency was also evaluated. One study found that higher operating speeds generally led to fewer accidents [19]. This was attributed to the influence of geometric features on drivers' speed. While curves pose more risk, they are negotiated at lower speeds. Another study found that accident severity was affected by operating speed with a $1 \%$ increase in the average operating speed resulting in a $0.074 \%$ decrease in the number of minor injuries and a $0.095 \%$ increase in the number of fatalities [20]. Other research found that higher speed limits increased the probability of a more severe accident and that accident severity increased outside level and straight roadways [21, 22].

In regards to the segment length used for crash analysis outside intersection-related sites, one study found that there is no definitive length which performs better than any other and that the length of segment used depends solely on the type of research being done [23]. Rather than focusing solely on fixed length segments, a study by Koorey [24] concluded that variable length segments perform better in crash analysis. Because fixed segments are based on length and variable segments are based on geometric and environmental features, the latter more accurately represents roadway characteristics. Similar conclusions to those of Koorey were reported by Mayora and Rubio [25], who used both fixed and variable length segments to investigate crash rate prediction in Spain's two lane rural roads. They found that fixed length segments did not perform as well in correlation analysis as compared to variable length segments. For both segment types, access control, sight distance, and design consistency were found to have the highest correlation to crash rates. Sight distance was also found to be significant in a study done by Caliendo and Lamberti [5] on four lane median separated roads.

There are good reasons to believe that, despite the many studies in the literature that attempted to understand the relationships between crash occurrence and traffic and roadway features, those relationships are not fully understood with a reasonable level of certainty. The current study is an effort to contribute to the existing limited knowledge using the US-191 corridor case study presented in this paper.

\section{Study site}

The site investigated in this study consists of a 15.7-mile stretch of the US-191 highway running through the Gallatin Canyon (between mileposts 48.3 and 64) in southwest Montana. This highway segment was designed in 1954 to accommodate the natural contours of the Gallatin River, creating many sharp curves with limited sight distance for drivers at a few locations. This particular stretch was chosen because it was identified as one of the high crash 
rural corridors in the state of Montana [26]. Currently, it has a posted speed limit of $60 \mathrm{mph}$ with advisory speed limits on some of its restricting curves. In 2008, the AADT at this corridor was in the order of 6300 vehicles per day [27].

\section{Study design}

\subsection{Approach}

The crash corridor in this study involved several restrictive curves, non-restrictive curves, and tangent segments. Restrictive curves contain limited sight distance and/or small radii that restrict travel speed relative to the speed limit, while non-restrictive curves have sufficient sight distance and greater radii that do not restrict travel speed. Tangent segments exist between horizontal curves and constitute the majority of corridor by distance. This study attempted to investigate crash experience at the corridor level using a mesoscopic approach. Specifically, while no focus was given to any particular location within the corridor and the whole corridor was treated uniformly, the analysis involved portioning the corridor into very short segments, each of which was associated with several descriptors using spatial, geometric, and speed data. The unit length used for the segment was one tenth of a mile, which is considered very short given the rural context of the corridor. An important consideration in selecting this length was the resolution of the spatial information for crash data obtained from the Montana Department of Transportation (MDT). Using crash data and segment descriptors, the analysis in this study attempted to identify the underlying relationships between crash experience on one hand and road geometry and speed characteristics on the other hand.

\subsection{Data collection and processing}

Significant amounts of data were needed in this investigation including data on crash experience, horizontal alignment, roadside features, and prevailing free-flow speed.

- Crash data Ten years of crash data for the study corridor were obtained from the MDT and included the location of the crash up to 0.1 mile accuracy, crash attributes, drivers' attributes, and limited environmental information. A total of 356 crashes occurred in the study corridor for the period between January 1, 2000 and December 31, 2009.

- Horizontal alignment Detailed engineering design drawings for the study corridor were obtained from the MDT and used to extract information on horizontal alignment related to this study.

- Roadside features Information on roadside features was gathered by the research team using detailed field observations. Four aspects of roadside features were of interest to this study: side slope, presence of guardrail, presence of fixed objects, and the relative location of the valley/river (or otherwise mountain wall) to the roadside. Only those objects within 30 feet of the travel lane were included in the study.

- Speed data Speed data was collected at 44 locations along the study corridor for the two directions of travel. Speed radar guns were used to collect speed observations of vehicles traveling at headways of six seconds or greater to ensure that vehicles were not following (interacting) with the lead vehicles. The appropriate procedures were followed when using the equipment to attain high accuracy of speed measurements. Specifically, the distance from the road's centerline and between the vehicle and observation point was measured in the field, especially on tangent segments. This information was used later to adjust for the effect of the firing angle between the direction of motion and the radar line, as deemed applicable. On most curved sections, the device was aimed at vehicles at the appropriate angle, thus requiring no further adjustment. Further, the research team tried to take speed observations without being seen by drivers to avoid any effect on the observed speeds. The sample size for each data set was estimated using a level of significance of 0.1 , speed standard deviation of $5 \mathrm{mph}$, and a tolerance of $\pm 1.5 \mathrm{mph}$. The type of vehicle was also included in the speed study field sheet using three main classes: cars, recreational vehicles, and heavy vehicles including trucks and buses.

The objective of conducting these extensive speed measurements was to establish a free-flow speed profile along the study corridor. In establishing the speed profile, it was assumed that vehicle speed on tangents and very flat curves remained relatively constant outside the acceleration and deceleration areas. Using this free-flow speed profile, deviation from the speed dictated by radius, sight distance, or speed limit, whichever was lowest, was derived and used in the analysis. The term used to describe this deviation is $\Delta \mathrm{V}$.

\subsection{Study crash indicators}

This study investigated crash experience on the US-191 corridor using four different crash indicators; crash frequency, severity index, combined safety index, and crash rate per mile distance. The crash frequency is the number 
of crashes occurring during the study period for all crash types or for a specific crash type such as the frequency of PDO, injury, or fatal crashes. The severity index takes into account the severity of crashes regardless of its frequency. To calculate the severity index, weights are to be applied to the different severity-type crashes. In this study, weights applied to the PDO, injury, and fatal crashes are 1, 5, and 15 , respectively. The severity index is found by multiplying the frequency of each type of crash by its assigned weight, summing all values, and dividing the sum by the total frequency of crashes. The combined safety index takes both frequency and severity into consideration in describing crash experience. Again, this index utilizes different weights for each type of crash, i.e., PDO, injury, and fatal crashes. The weights used in this study are the same as those used for the severity index discussed earlier. To calculate the combined safety index, frequency of the PDO, injury, and fatal crashes are multiplied by their assigned weights and summed together into a single index value. Finally, crash rate by distance (in miles) was also utilized in the analyses involved in this study.

\section{Study results}

\subsection{Preliminary examination of crash data}

Out of the 356 crashes investigated in this study, 86 injury crashes and 6 fatal crashes occurred in the study corridor over the ten-year study period. Of all the drivers involved in these accidents, around $74 \%$ were male drivers while the remaining $26 \%$ were female drivers. The highest proportion of drivers involved in crashes belongs to the age group 20-29 years, followed by the age groups 30-39, and $40-49$ years, respectively. Trucks claimed $13 \%$ of the total crashes in the corridor. In terms of light condition, $61 \%$ of crashes occurred during daylight, $34 \%$ during dark, and the remaining $5 \%$ of crashes occurred during dawn and dusk. Ice, snow, and slush on pavement were associated with $43.5 \%$ of the crashes investigated by this study. Figure 1 shows the breakdown of corridor crashes by crash type over the ten-year study period. More than half of all crashes were ROR, with animal-vehicle collisions, and rear end crashes being the next most common types of crashes, respectively.

Table 1 shows the number of vehicles involved in crashes broken down by crash severity for all crashes investigated by this study. The most important trend shown in this table is the fact that multiple-vehicle crashes represent higher percentages of fatal and injury crashes compared with the PDO crashes. The relationship between the number of vehicles involved in a crash and crash severity was found significant using the Pearson $\chi^{2}$ test shown in

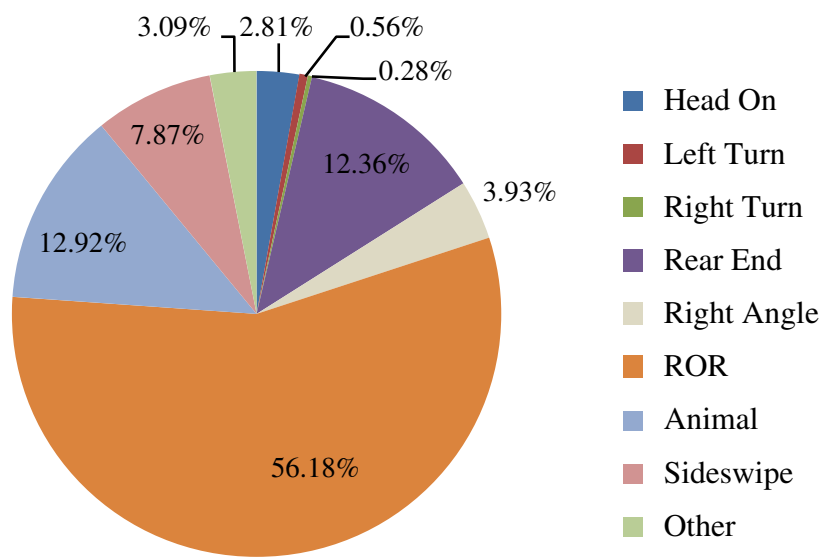

Fig. 1 Crashes on US-191 corridor broken down by crash type

Table 1. Using crash location relative to the corridor, the frequencies of PDO, injury, and fatal crashes along the corridor are shown in Fig. 2. As clearly shown in this figure, some segments have higher frequencies, severities, or both when compared to other segments in the corridor. Specifically, the segment between milepost 61 and 62 had the highest frequency among all other segments in the corridor. However, three out of the six fatal crashes that took place in the corridor over ten years occurred in the segment between mileposts 52 and 53 .

\subsection{Crash-alignment relationship}

Each 0.1 mile segment of the study corridor was assigned an alignment descriptor which describes the most restrictive alignment within the segment. Tangent, non-restrictive, and restrictive horizontal curvatures were assigned to each segment. Non-restrictive curvatures are defined as those values that would safely allow vehicles to negotiate curves at speeds equal or greater than the posted speed limit. The restrictive curves, on the other hand, would force drivers to travel at speeds lower than the posted speed limit if they wanted to safely negotiate the curve. Those determinations are made using the well-known highway geometric design equations. Figure 3 illustrates the relationships between degree of curvature and crash frequency, crash severity, and the combined safety index. While the scatter plots do not clearly show a strong relationship between the variables, a relatively fuzzy trend can be discerned between the degree of curvature on one hand and crash frequency and the combined safety index on the other hand in both directions of travel. No specific trend can be discerned for the relationship between degree of curvature and crash severity. This is somewhat logical in that sharper curves may increase the likelihood of vehicles leaving the travel way (and consequently involved in a crash) while the severity of the crash is more dependent on other factors such as roadside design features. 
Table 1 Number of crashes by severity type and number of vehicles involved in crash

\begin{tabular}{lclll}
\hline & PDO & Injury & Fatality & Pearson $\chi^{2}$ test \\
\hline One-vehicle crash & $195(73.9 \%)$ & $49(57 \%)$ & $2(33.4 \%)$ & $\chi^{2}=23.239$ \\
Two-vehicle crash & $65(24.6 \%)$ & $28(32.6 \% \%)$ & $4(66.6 \%)$ & $P<0.001$ \\
Three-vehicle crash & $4(1.5 \%)$ & $9(10.4 \%)$ & $0(0.0 \%)$ & $6(100 \%)$ \\
Total & $264(100 \%)$ & $86(100 \%)$ & & \\
\hline
\end{tabular}

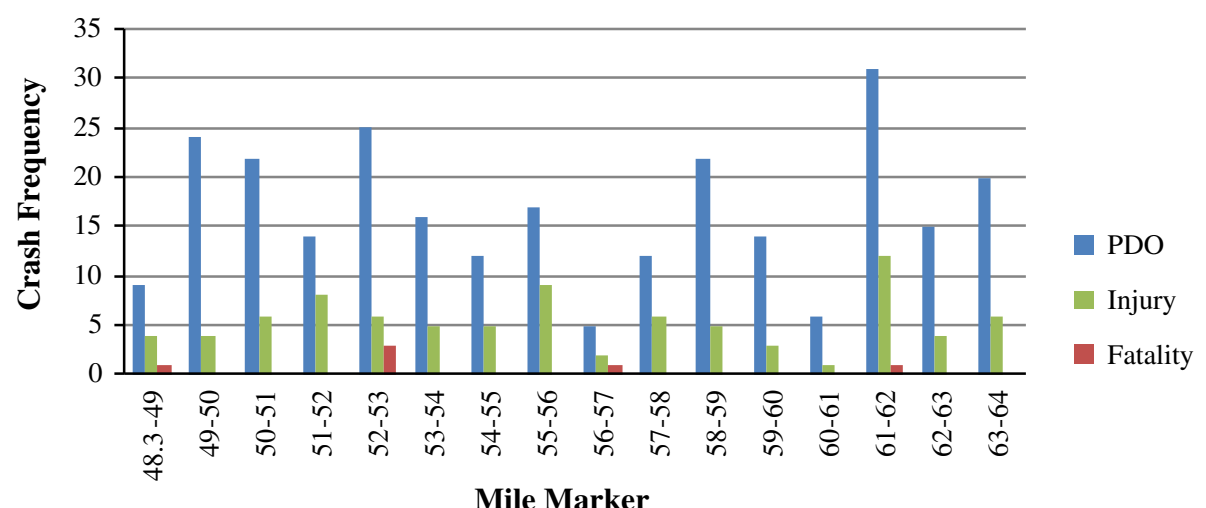

Fig. 2 Frequency of PDO, injury, and fatal crashes per 1-mile segment along study corridor

To further assess the fuzzy trends shown in Fig. 3, crash rate per mile per year was established for the three types of segments; those involving restrictive curves, those involving non-restrictive curves, and tangent segments in the two directions of travel. The results are shown in Table 2. Two important trends are clearly exhibited in this table. The first trend is that the crash rate is higher for restrictive curves, followed by non-restrictive curves, and tangent segments, respectively. This trend is consistent across crash type by severity in the two directions of travel. The other trend that can easily be discerned in this table is the fact that crash rates in the northbound direction are higher than those in the southbound direction. One possible explanation is that higher average speeds were observed in the northbound direction as compared to the southbound direction.

\subsection{Examination of the crash-speed relationship}

The speed variable that is used in this study $(\Delta V)$ is the difference between prevailing free-flow speed and speed dictated by radius or sight distance on restrictive curves and the difference between free-flow speed and speed limit on non-restrictive curves and tangents. It is believed that this variable is mainly a function of highway alignment. Figure 4 shows scatter plot of free-flow speed and $\Delta V$ with respect to the degree of curvature within the study corridor in the two directions of travel. The general trend shown in this figure is that the higher the degree the curvature, the lower the free-flow speed. This is consistent with the expectation that horizontal curvatures restrict the selected free-flow speed on high speed highway facilities. In regards to $\Delta V$, it is clear in this figure that higher $\Delta V$ values are generally associated with sharper curves, i.e., higher degrees of curvature.

To investigate the crash experience as a function of $\Delta V$, crash rate per mile per year was established for a three-tier $\Delta V$ classification for each severity-type crash in the two directions of travel. The results of this analysis are presented in Table 3. A closer examination of the crash rates in this table reveals a clear trend; the greater the value of $\Delta V$, the greater the crash rate. This trend is consistent throughout the table with one minor exception. Despite this observed consistency, the relationship between $\Delta V$ and crash severity was not found significant as suggested by the Pearson $\chi^{2}$ results shown in Table 3 .

\subsection{Examination of crash relationship with roadside safety features}

Four highway roadside features that are thought to have relationships with safety were investigated in this study. These features involve the presence of guardrail, side slope, the presence of fixed objects, and the presence of valley/river or the mountain wall adjacent to the travel lane. Figure 5 shows the average crash frequency, severity index, and combined safety index value for the aforementioned variables in the two directions of travel. 

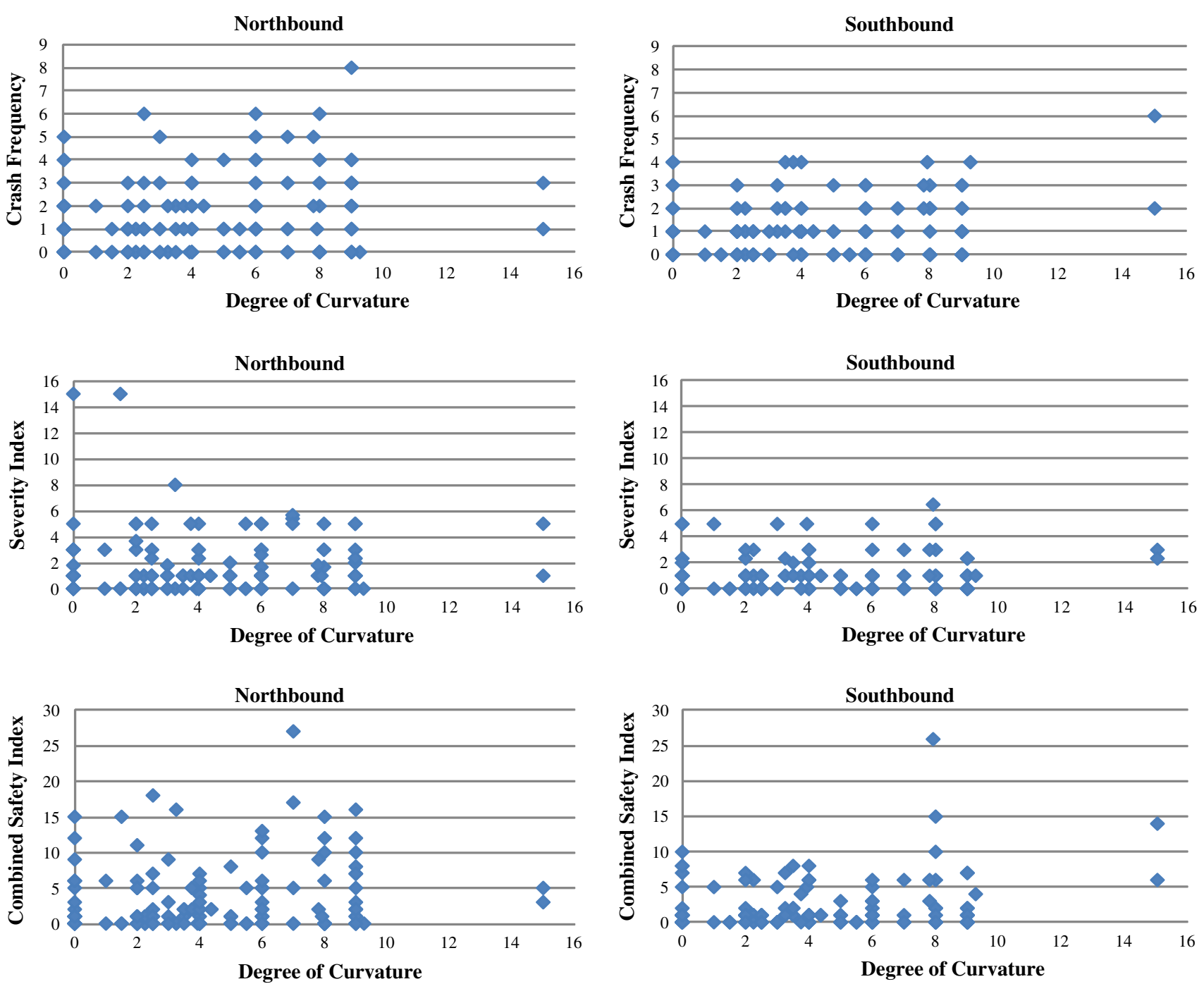

Fig. 3 Crash frequency, severity index, and combined safety index for various degrees of curvature in the two directions of travel

Table 2 Crash rate per mile per year on US-191 based on direction, severity, and alignment

\begin{tabular}{lllll}
\hline & $\begin{array}{l}\text { Restrictive } \\
\text { Curves }\end{array}$ & $\begin{array}{l}\text { Non-restrictive } \\
\text { Curves }\end{array}$ & Tangents & Total \\
\hline North PDO & 1.584 & 0.827 & 0.471 & 0.945 \\
South PDO & 1.158 & 0.735 & 0.358 & 0.740 \\
North injury & 0.670 & 0.294 & 0.151 & 0.364 \\
South injury & 0.345 & 0.202 & 0.113 & 0.217 \\
North fatal & 0.041 & 0.037 & 0.019 & 0.032 \\
South fatal & 0.020 & 0.000 & 0.000 & 0.006 \\
Total & 3.819 & 2.096 & 1.112 & 2.304 \\
\hline
\end{tabular}

In regards to the presence of guardrail, the overall trend that could be discerned from Fig. 5 is that segments with no guardrail installations had higher average values for crash indicators as compared to segments with guardrail installations. However, the effect of the amount of guardrail installations on the crash indicators may not be completely consistent. To more accurately assess this trend, the average safety indicators were calculated for segments with and without guardrail installations and the results are shown in Table 4. As clearly shown in this table, guardrail installations are consistently associated with a reduction in crash frequencies and severities, and consequently in the combined safety index. $t$ tests were conducted at the $90 \%$ confidence level to determine the significance of these reductions. Only differences in the crash frequency and combined safety index for the northbound direction were found significant as shown in Table 4.

Side slope is also thought to have an effect on the likelihood of vehicles recovering from an errant maneuver and on the severity of ROR. Figure 5 shows that moderate side slopes are associated with the highest crash indicators in both directions of travel. This is somewhat unexpected 

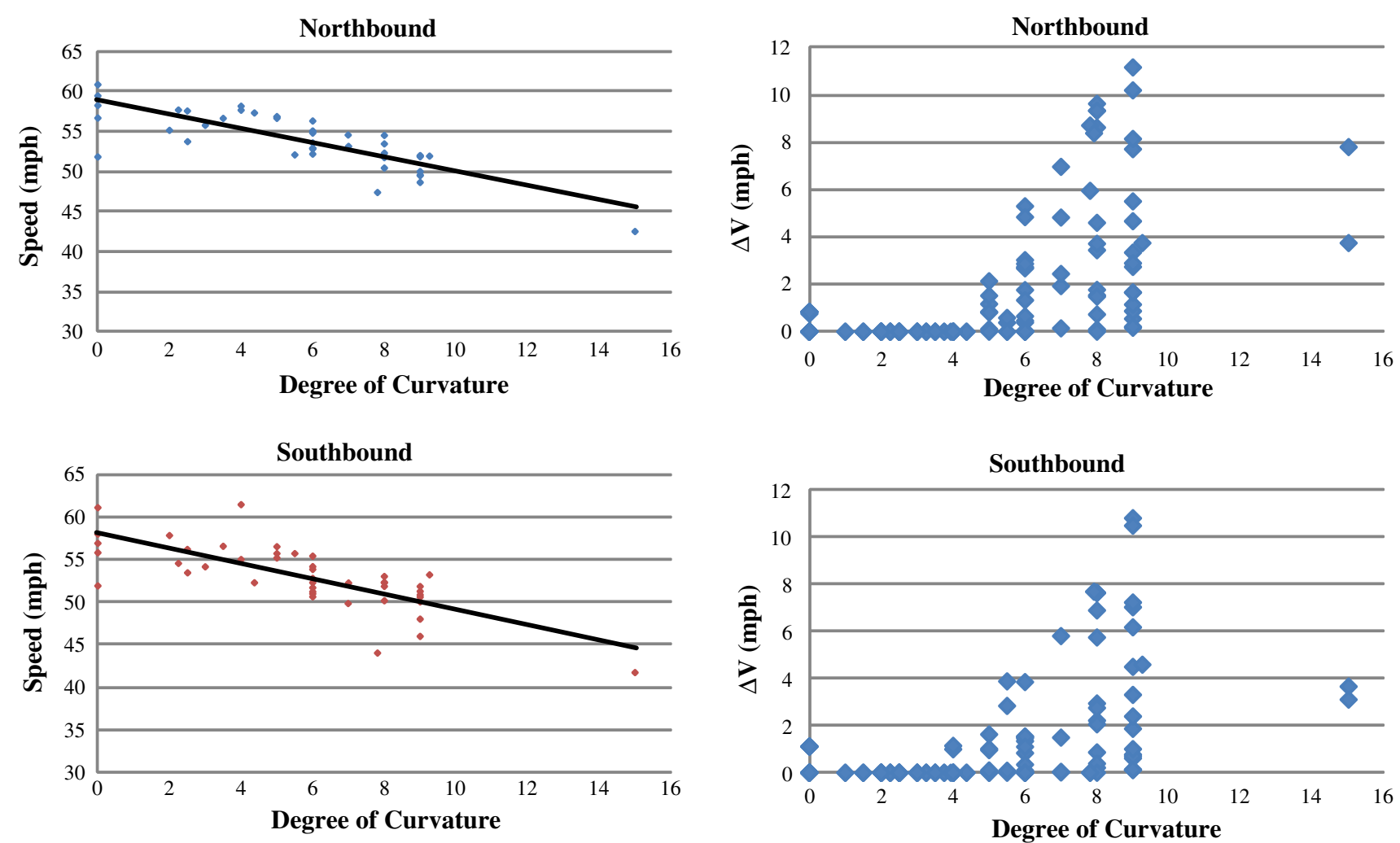

Fig. 4 Scatter plots of free-flow speed and $\Delta V$ versus degree of curvature

Table 3 Crash rate per mile per year as a function of $\Delta V$ for various crash types by severity

\begin{tabular}{lllcc}
\hline & $\Delta V=0$ & $0<\Delta V<4$ & $4 \leq \Delta V \leq 12$ & Pearson $\chi^{2}$ test \\
\hline NB-PDO & $77(0.828)$ & $48(1.043)$ & $22(1.211)$ & $\chi^{2}=0.492$ \\
NB-Injury and Fatal & $29(0.376)$ & $37(0.787)$ & $11(0.579)$ & $P=0.781$ \\
SB-PDO & $68(0.701)$ & $11(0.234)$ & $11(0.786)$ & $\chi^{2}=4.629$ \\
SB-Injury and Fatal & $16(0.165)$ & $8(0.571)$ & $P=0.099$ \\
\hline
\end{tabular}

as steeper side slopes should pose more hazards to the traveling public and contribute to the number and severity of crashes. To investigate this unexpected trend, a breakdown of study segments by guardrail installation and side slope was established as shown in Table 5.

As shown in Table 5, the guardrail installation is overrepresented on segments with steep side slopes, a matter that is expected. This is believed to explain the lower average crash indicators for segments with steep slopes as guardrails prevent most vehicles from leaving the road and thus contribute to lower crash frequency and severity. The relationship between side slope and percent guardrail installation was found significant as suggested by the Pearson $\chi^{2}$ results.

In regards to the fixed objects at the roadside, the research hypothesis is that the presence of fixed objects may contribute to the frequency and severity of crashes. A closer look at Fig. 5 shows a general consistency with this logical hypothesis, with the northbound direction being more consistent as compared to the southbound direction. To more quantitatively assess the effect of fixed objects on crash experience, the average crash indicator values for segments with and without fixed roadside objects were calculated and presented in Table 6 .

This table clearly shows that segments with no fixed roadside objects consistently exhibited lower crash indicators compared with those that have fixed objects. This supports the logical hypothesis about the hazards posed by the presence of fixed objects at the roadside. While the mean crash indicators supported the aforementioned hypothesis, $t$ tests conducted at the $90 \%$ confidence level found the difference in crash indicators for sections with and without roadside objects significant only for the combined safety index in the northbound direction. 

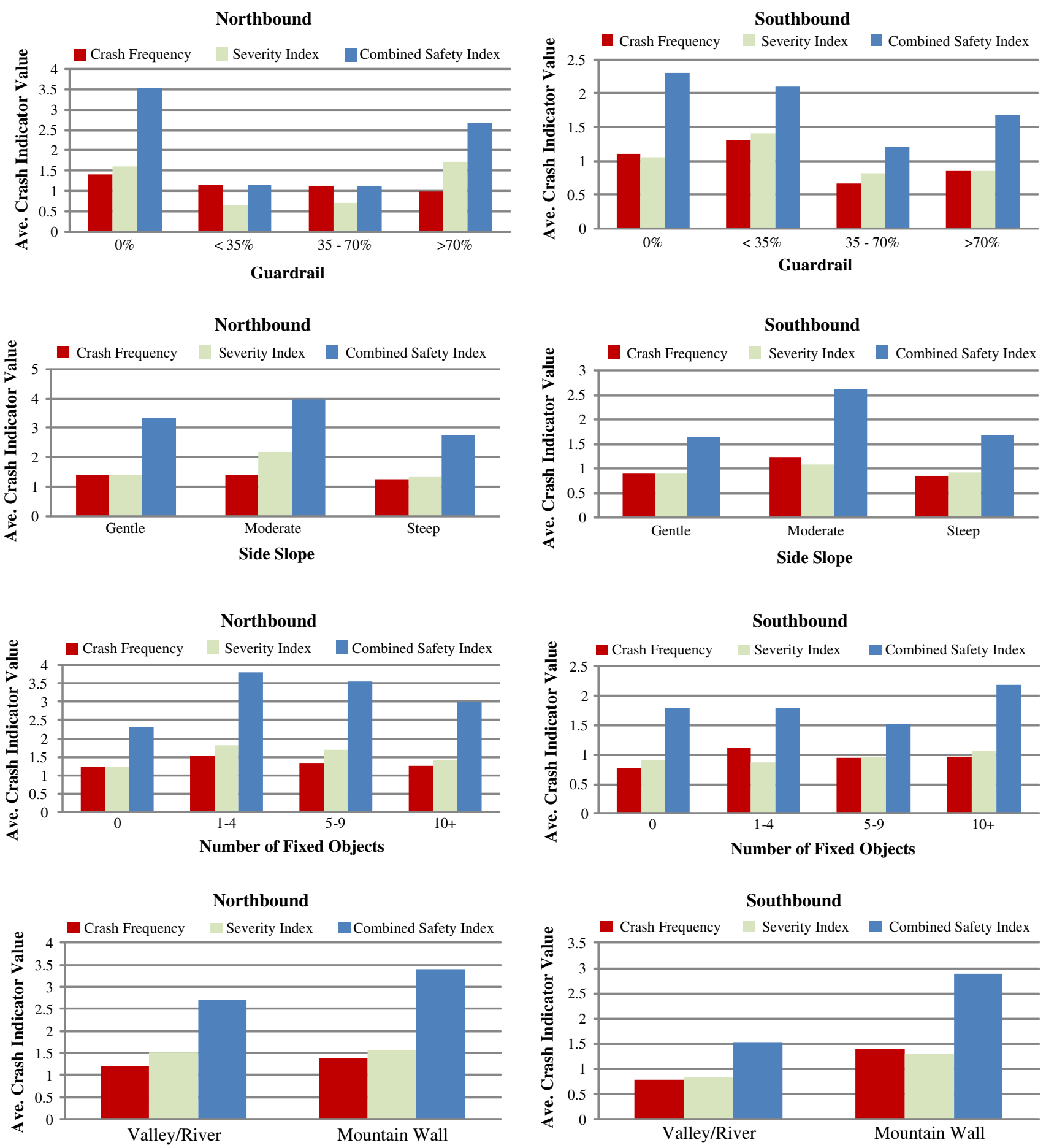

Fig. 5 Average crash frequency, severity index, and combined safety index in relation to the various roadside features

One other roadside feature that was investigated by this study is the adjacent roadside being on the side of the valley/river or on the other side, which is in most parts the mountain wall. The study corridor is a mountainous corridor with relatively winding alignment, and therefore, the valley/river and the mountain sides are often present in the roadway cross section with the exception of limited distances where the mountain is not in close proximity to the roadway. The trend shown in Fig. 5 is that the mountain wall side is associated with higher crash frequency and severity, and thus a higher combined safety index. To further understand this trend, it was necessary to examine the guardrail installation for segments along the valley side versus those that are 
Table 4 Average crash frequency, severity index, and combined safety index for segments with and without guardrail installations

\begin{tabular}{lllll}
\hline & No guardrail & Guardrail & \% Difference & $\begin{array}{c}t \text { test } \\
90 \% \text { Confidence }\end{array}$ \\
\hline NB-Crash Frequency & 1.413 & 1.054 & 25.4 & $\underline{\text { Significant }}$ \\
NB-Severity Index & 1.614 & 1.355 & 16.0 & Insignificant \\
NB-Combined Safety Index & 3.545 & 2.135 & 39.8 & Significant \\
SB-Crash Frequency & 1.098 & 0.866 & 21.2 & Insignificant \\
SB-Severity Index & 1.052 & 0.900 & 14.4 & Insignificant \\
SB-Combined Safety Index & 2.311 & 1.649 & 28.6 & Insignificant \\
\hline
\end{tabular}

Table 5 Information on guardrail installations for segments with different side slopes

\begin{tabular}{|c|c|c|c|c|c|}
\hline Guardrail \% & $0 \%$ & $<35 \%$ & $35 \%-70 \%$ & $>70 \%$ & Pearson $\chi^{2}$ test \\
\hline \multicolumn{6}{|l|}{ Northbound } \\
\hline Gentle slope & $35(97.2 \%)$ & $0(0 \%)$ & $1(2.8 \%)$ & $0(0 \%)$ & $\chi^{2}=26.541$ \\
\hline Moderate slope & $34(82.9 \%)$ & $4(9.8 \%)$ & $1(2.4 \%)$ & $2(4.9 \%)$ & $P<0.001$ \\
\hline Steep slope & $52(64.2 \%)$ & $2(2.4 \%)$ & $5(6.2 \%)$ & $22(27.2 \%)$ & \\
\hline \multicolumn{6}{|l|}{ Southbound } \\
\hline Gentle slope & $15(68.2 \%)$ & $3(13.6 \%)$ & $2(9.1 \%)$ & $2(9.1 \%)$ & $\chi^{2}=22.934$ \\
\hline Moderate slope & $18(46.1 \%)$ & $4(10.3 \%)$ & $3(7.7 \%)$ & $14(35.9 \%)$ & $P=0.001$ \\
\hline Steep slope & $28(28.9 \%)$ & $3(3.1 \%)$ & $10(10.3 \%)$ & $56(57.7 \%)$ & \\
\hline
\end{tabular}

Table 6 Average crash frequency, severity index, and combined safety index for segments with and without fixed roadside objects

\begin{tabular}{|c|c|c|c|c|}
\hline & Objects & No objects & $\%$ difference & $\begin{array}{l}t \text { test } \\
90 \% \text { Confidence }\end{array}$ \\
\hline $\mathrm{NB}-\mathrm{Crash}$ frequency & 1.346 & 1.227 & 8.8 & Insignificant \\
\hline NB-Severity index & 1.603 & 1.242 & 22.5 & Insignificant \\
\hline NB-Combined safety index & 3.360 & 2.318 & 31.0 & $\underline{\text { Significant }}$ \\
\hline SB-Crash frequency & 1.017 & 0.769 & 24.3 & Insignificant \\
\hline SB-Severity index & 0.973 & 0.915 & 6.0 & Insignificant \\
\hline SB-Combined safety index & 1.941 & 1.795 & 7.5 & Insignificant \\
\hline
\end{tabular}

Table 7 Information on guardrail installations for segments along the valley and the mountain sides

\begin{tabular}{|c|c|c|c|c|c|}
\hline Guardrail \% & $0 \%$ & $<35 \%$ & $35 \%-70 \%$ & $>70 \%$ & Total $(\%)$ \\
\hline \multicolumn{6}{|l|}{ Northbound } \\
\hline Mountain wall & $105(92.1 \%)$ & $5(4.4 \%)$ & $0(0.0 \%)$ & $4(3.5 \%)$ & 100 \\
\hline Valley/river & $16(36.4 \%)$ & $1(2.3 \%)$ & $7(15.9 \%)$ & $20(45.4 \%)$ & 100 \\
\hline \multicolumn{6}{|l|}{ Southbound } \\
\hline Mountain wall & $40(90.9 \%)$ & $3(6.8 \%)$ & $0(0.0 \%)$ & $1(2.3 \%)$ & 100 \\
\hline Valley/river & $21(18.4 \%)$ & $7(6.1 \%)$ & $15(13.2 \%)$ & $71(62.3 \%)$ & 100 \\
\hline
\end{tabular}

along the mountain side. The results are presented in Table 7 below.

It is evident from the numbers in this table that guardrail installation is heavily overrepresented at segments along the valley side compared with those along the mountain side. This may partly explain the higher crash indicator values for those segments along the mountain side.
5.5 Multivariate analysis of crash data

After observing some of the trends between the safety indicators on one hand and speed, road geometry, and roadside features on the other hand, multivariate linear regression and correlation analyses were performed to further evaluate the relationships between these variables. 
Table 8 summarizes the results of the regression analysis which show the relationship between the response variable (safety indicators) and predictor variables (speed, geometry and roadside features) in the southbound direction.

Upon examining this table, the following observations can be made:

(1) Only two models were found statistically significant at the $95 \%$ confidence level as affirmed by the $F$-test results. Those models are for crash frequency and the combined safety index. The model for severity index was not found statistically significant.

(2) The coefficients of determination $\left(R^{2}\right)$ are relatively low for the two models that were found significant with 0.333 and 0.350 for the crash frequency and the combined safety index models, respectively. This shows that little variations in the safety indicators are explained by the predictor variables.

(3) The degree of curve and the presence of valley versus river at roadside were both found significant for the crash frequency model, while only $\Delta V$ was found significant in the combined safety index model at the $95 \%$ confidence level. The $t$ test results confirmed that all other variables investigated were not found significant at the $95 \%$ confidence level.

Correlation analysis in the southbound direction was performed using the same above variables to gain more insights into the safety effects of speed, geometry, and roadside features. Correlation results are provided in Table 9 below.

As clearly shown in Table 9, the correlation coefficients were low overall with the highest coefficient being 0.272 between $\Delta V$ and the combined safety index. However, those correlation coefficients have all exhibited logical relationships with the three safety indicators.

Similar regression and correlation analyses were performed using the data in the Northbound direction, however, the models developed and the correlations found revealed even weaker effects of the study variables on safety indicators. As such, results were not included in the current section.

\section{Summary of findings}

The current study presents a crash analysis along a rural corridor in southwest Montana. The study corridor is located on US-191 within the Gallatin Canyon between the cities of Bozeman and Big Sky. The approach used in this study is macroscopic in that it examined the whole corridor systematically without focusing on any specific crash or any particular site. However, the approach can also be viewed as microscopic in that detailed crash-related information at a relatively high resolution was used where every tenth of a mile was characterized as an individual segment within the corridor. The approach could be applied at higher resolution should more accurate crash location information become available. The study investigated crash experience at the study corridor along with some of the fundamental relationships between crashes on one hand and roadway alignment, roadside features, and speed on the other hand. These relationships shed light on many of the crash causal factors in a rural environment. The major findings of this study are:

- While ROR constituted more than $56 \%$ of total crashes, crashes involving multiple vehicles tended to be higher in severity. Further, ice, snow, and slush on pavement were associated with more than $43 \%$ of all crashes investigated by this study.

- Horizontal curvatures were found to have strong association with higher crash frequencies even on flat curves that would not restrict the traveling speed based on the highway design equations. This requires a rethinking of the speed management techniques currently in use at the location of curves.

- Higher crash frequencies were also found to be associated with the difference between prevailing free-flow speed and the speed dictated by design equations (at segments with small radii or limited sight distance) or speed limit.

- Safety benefits of guardrails were clearly reflected in the results of this investigation as evidenced by the lower crash frequency and severity despite the more

Table 8 Summary results from multivariate linear regression analysis at US 191 Corridor (Southbound)

\begin{tabular}{|c|c|c|c|c|c|c|c|c|c|}
\hline \multirow[t]{2}{*}{ Safety indicator } & \multicolumn{3}{|c|}{ Regression model } & \multicolumn{6}{|c|}{$P$ value from $t$ test $^{\mathrm{b}, \mathrm{c}}$} \\
\hline & $F$ test $^{\mathrm{a}}$ & $R^{2}$ & SE & $\mathrm{DOC}$ & $\Delta \mathrm{V}$ & Guardrail & Sideslope & Roadside Objects & Valley/river \\
\hline Crash frequency & 0.0060 & 0.333 & 1.14 & 0.026 & 0.561 & 0.814 & 0.486 & 0.956 & 0.025 \\
\hline Severity index & 0.2510 & 0.223 & 1.33 & 0.646 & 0.187 & 0.935 & 0.921 & 0.740 & 0.134 \\
\hline Combined safety index & 0.0027 & 0.350 & 3.25 & 0.231 & 0.013 & 0.681 & 0.709 & 0.840 & $(0.094)$ \\
\hline
\end{tabular}

${ }^{a}$ Values underlined in italic refer to models that were found significant using the $F$ test

b Values in bold are for coefficients that were found significant using the $t$ test

c Values in brackets are those that passed significance testing at the $90 \%$ confidence level only 
Table 9 Correlation analysis results between safety indicators and study variables

\begin{tabular}{lllllll}
\hline & DOC & Average overall $\Delta \mathrm{V}$ & Guardrail & Sideslope & Roadside objects & Valley/river? \\
\hline Crash frequency & 0.190 & 0.152 & -0.110 & -0.064 & 0.036 & -0.225 \\
Severity index & 0.085 & 0.140 & -0.081 & -0.019 & 0.051 & -0.158 \\
Combined safety index & 0.189 & 0.272 & -0.091 & -0.041 & 0.045 & -0.180 \\
\hline
\end{tabular}

hazardous roadside features at the locations of guardrail installations.

- Results suggest that crash frequency and severity were associated with the presence of fixed roadside objects and the steepness of side slope along the study corridor.

- While the deep valley may pose significant hazard for run-of-the-road vehicles, segments along the valley were associated with lower crash frequency and severity. This is believed to be related to guardrail installation that exists more on this side of the road. These results suggest the effectiveness of guardrails as a low-cost safety countermeasure in many hazardous rural locations.

- The multivariate regression analysis did not reveal further insights and evidence about the relationships between the speed, geometry, and roadside features with safety indicators. This is despite the fact that most of those variables were observed to have clear connection with the crash indicators using the preliminary analyses presented earlier in this paper. This suggests that crash occurrence is related to some other important factors that were not investigated in this study such as the driver and weather conditions.

The authors would recommend a few measures in an attempt to reduce the high crash rates at this corridor. Among these measures are speed management strategies (e.g., variable speed limit) that would control speeds at the more hazardous segments in this corridor. This is essential especially since a significant number of crashes occur during inclement weather events. The use of guardrail at other parts of the corridor, not necessarily along steep side slopes, could help further improve safety within the corridor, as suggested by study results. Another safety measure is the use of ITS warning systems alerting drivers of pavement condition during and after inclement weather events.

Acknowledgements The authors would like to acknowledge the financial support to this research by the National Science Foundation (NSF) through the Western Transportation Institute (WTI) of Montana State University. The assistance of Mr. Pierre Jomini and Mr. Scott Keller of the Montana Department of Transportation (MDT) was critical to this project and was acknowledged by the authors.

Open Access This article is distributed under the terms of the Creative Commons Attribution License which permits any use, distribution, and reproduction in any medium, provided the original author(s) and the source are credited.

\section{References}

1. National Highway Traffic Safety Administration (2013). Early Estimate of Motor Vehicle Traffic Fatalities in 2012. Publication DOT HS 811 741. NHTSA, U.S. Department of Transportation, May 2013

2. Anderson I, Krammes R (2000) Speed reduction as a surrogate for accident experience at horizontal curves on rural two-lane highways. Transportation Research Record No. 1701, Transportation Research Board, Washington D.C., pp 86-94

3. Lamm R, Beck A, Ruscher T, Mailaender T, Cafiso S, La Cava G (2007) How to make two-lane rural roads safer: scientific background and guide for practical application. WIT Press, Massachusetts

4. Garber N, Kassebaum E (2008) Evaluation of crash rates and casual factors for high-risk locations on rural and urban two-lane highways in Virginia. Publication FHWA/VTRC 09-R1. Virginia Transportation Research Council

5. Caliendo C, Lamberti R (2001) Relationships between Accidents and Geometric Characteristics for Four Lanes Median Separated Roads. In: Proceeding of the Road Safety on Three Continents, Moscow, Russia, September 19-21, 2001

6. Cenek P, Davies R, Henderson R (2012) Crash risk relationships for improved road safety management. Publication 488. New Zealand Transport Agency

7. Hauer E (1995) Safety and the choice of degree of curve. Transportation Research Record No. 1665, Transportation Research Board, Washington, D.C, pp 22-27

8. Hadi M, Aruldhas J, Chow L, Wattleworth J (1995) Estimating safety effects of cross-section design for various highway types using negative binomial regression. Transportation Research Record No. 1500, Transportation Research Board, Washington, D.C., pp 169-177

9. Gross F, Jovanis P, Eccles K (2009) Safety effectiveness of lane and shoulder width combinations on rural, two-lane, undivided roads. Transportation Research Record No. 2103, Transportation Research Board, Washington, D.C., pp 42-49

10. Karlaftis M, Golias I (2002) Effects of road geometry and traffic volumes on rural roadway accident rates. Accid Anal Prev 34(3):357-365

11. Bester C, Makunje J (1995) The effect of rural road geometry on safety in Southern Africa. In: Proceeding of the International Symposium on Highway Geometric Design Practices, Boston, August 30-September 1, 1995

12. Council F (1998) Safety benefits of spiral transitions on horizontal curves on two-lane rural roads. Transportation Research Record No. 1635, Transportation Research Board, Washington, D.C., pp $10-17$

13. Farah H, Bekhor S, Polus A (2009) Risk evaluation by modeling of passing behavior on two-lane rural highways. Accid Anal Prev 41(4):887-894

14. Zhong C, Sisiopiku V, Ksaibati K, Zhong T (2011) Crash prediction on rural roads. In: Proceeding of the 3rd International Conference on Road Safety and Simulation, Indianapolis, Indiana, September 14-16, 2011 
15. Andjus V, Maletin M (1998) Speeds of cars on horizontal curves. Transportation Research Record No. 1612, Transportation Research Board, Washington, D.C., pp 42-47

16. Collins J, Fitzpatrick K, Bauer K, Harwood D (1999) Speed variability on rural two-lane highways. Transportation Research Record No. 1658, Transportation Research Board, Washington, D.C., pp 60-69

17. Tate F, Turner S (2007) Road geometry and drivers' speed choice. Road Transp Res J Aust N Z Res Pract 16(4):53-64

18. Garber N, Ehrhart A (2000) Effect of speed, flow, and geometric characteristics on crash frequency for two-lane highways. Transportation Research Record No. 1707, Transportation Research Board, Washington, D.C., pp 76-83

19. Bird R, Hashim I (2006) Exploring the relationship between safety and consistency of geometry and speed on British roads. Transportation Research Board 2006 Annual Meeting. CD-ROM. TRB, Washington, D.C., pp 1-19

20. Wang C, Quddus M, Ison S (2009) The effects of area-wide road speed and curvature on traffic casualties in England. J Transp Geogr 17(5):385-395

21. Dissanayake S, Indike R (2006) Identification of factors leading to high severity of crashes in rural areas using ordered probit modeling. J Transp Res Forum 45(2):87-101
22. Malyshkina N, Mannering F, Labi S (2007) Influence of speed limits on roadway safety in Indiana. Publication FHWA/IN/ JTRP-2007/6. Joint Transportation Research Program

23. Thomas I (1996) Spatial data aggregation: exploratory analysis of road accidents. Accid Anal Prev 28(2):231-264

24. Koorey G (2009) Road data aggregation and sectioning considerations for crash analysis. Transportation Research Record No. 2103, TRB, Washington, D.C., pp 61-68

25. Mayora J, Rubio R (2003) Relevant variables for crash rate predictions in Spain's two lane rural roads. Transportation Research Board 2003 Annual Meeting. CD-ROM. TRB, Washington, D.C., pp 1-24

26. MDT State Highway Traffic Safety Bureau (2010) Traffic safety problem identification. Publication FFY 2009. Montana Department of Transportation, 2008. Accessed 30 July 2010

27. Montana Department of Transportation (2009) 2008 rural traffic flow map. http://www.mdt.mt.gov/publications/docs/datastats/ trafcount/2008_traffic_flow_map.pdf. Accessed 30 July 2010 